\title{
Vigilância da Hanseníase no Estado de Minas Gerais
}

\author{
Leprosy surveillance in Minas Gerais State \\ Vigiláncia de la Lepra en el Estado de Minas Gerais
}

\section{Maria Aparecida de Faria Grossi}

Coordenadora de Dermatologia Sanitária, Gerência de Vigilância em Saúde,

Superintendência de Epidemiologia, Secretaria de Estado de Saúde de Minas Gerais. Belo horizonte, MG

REBEn Como pode ser avaliado o atual estado de integração das Ações de Controle da Hanseníase na Atenção Básica?

O processo de integração das Ações de Controle de Hanseníase - ACH na Atenção Básica - AB tem ocorrido de modo gradual e progressivo, embora lento, desde os anos setenta. A descentralização da assistência às pessoas portadoras de hanseníase e/ou suas seQüelas, passou da responsabilidade do nível federal (SESP-FUNASA,) para a competência estadual e, a partir dos anos noventa, para o nível municipal.

A descentralização das $A C H$ para a $A B$ tem ocorrido de modo mais consistente nos últimos 10 anos, no entanto, ainda é observada concentração da assistência às pessoas com hanseníase e/ou suas seQüelas, nos serviços de referência.

Embora, a norma nacional seja clara Quanto à inclusão das $A C H$ na competência da $A B$, a cobertura destas ações não tem ultrapassado a $50 \%$ dos serviços de $A B$, na maioria dos estados.

\section{REBEn Quais são os aspectos Que facilitam e/ou dificultam essa integração?}

O principal aspecto Que tem facilitado a integração das $A C H$ na $A B$, sem dúvida, é a implantação da Estratégia do Programa de Saúde da Família Que aproximou, também, a pessoa com hanseníase da assistência necessária. Outros fatores a serem considerados foram: as inúmeras capacitações de profissionais realizadas por iniciativa dos diversos níveis de gestão da saúde; a garantia de distribuição gratuita dos medicamentos e os avanços científicos, Que permitiram a diminuição do tempo de tratamento, a perspectiva da cura e a desmistificação da doença com conseQüente redução do estigma.

Por outro lado, os fatores Que têm dificultado esta integração são, dentre outros: o despreparo e a desinformação dos gestores municipais Quanto à situação epidemiológica da hanseníase, ainda grave no Brasil; a visão antiga de que o controle dessa doença é de responsabilidade de centros especializados e não da $A B$; a dificuldade do serviço de referência de entender e incorporar $O$ seu novo papel de repassar experiência e apoiar a $A B$, e não mais de assumir integralmente o tratamento; a formação dos profissionais de saúde voltada para a especialização e ainda, a falta de informação atualizada sobre a hanseníase mantendo, entre os profissionais de saúde, o preconceito contra o doente.

\section{REBEn Que estratégias podem ser propostas para a efetivação desta integração?}

A principal estratégia seria a efetivação da rede de assistência, com a porta de entrada do sistema na $A B$, priorizando o papel da equipe de saúde da família, a existência de referências municipais, micro regionais, regionais, macro regionais, estaduais e nacionais, com competências bem definidas, sistema de monitoramento e avaliação bem estabelecido e supervisão sistemática e periódica das ACH em todos os níveis, assegurando a assistência integral à pessoa com hanseníase e/ou suas seQüelas. 